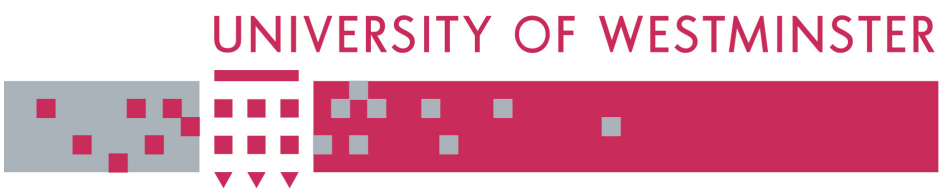

WestminsterResearch

http://www.wmin.ac.uk/westminsterresearch

\title{
A logistical perspective on the potential for modal shift of freight from road to rail in Great Britain.
}

\section{Allan Woodburn}

School of Architecture and the Built Environment

This is an electronic version of an article published in International Journal of Transport Management, 1(4), pp. 237-245, June 2004. Planning International Journal of Transport Management is available online at:

http://www.elsevier.com/wps/find/journaldescription.cws_home/621290/descri ption\#description

The WestminsterResearch online digital archive at the University of Westminster aims to make the research output of the University available to a wider audience. Copyright and Moral Rights remain with the authors and/or copyright owners. Users are permitted to download and/or print one copy for non-commercial private study or research. Further distribution and any use of material from within this archive for profit-making enterprises or for commercial gain is strictly forbidden.

Whilst further distribution of specific materials from within this archive is forbidden, you may freely distribute the URL of WestminsterResearch.

(http://www.wmin.ac.uk/westminsterresearch).

In case of abuse or copyright appearing without permission e-mail wattsn@wmin.ac.uk. 


\title{
A Logistical Perspective on the Potential for Modal Shift of Freight from Road to Rail in Great Britain
}

Dr Allan G. Woodburn

Senior Lecturer in Freight and Logistics

Transport Studies Group, Department of Urban Development and Regeneration

University of Westminster, London, NW1 5LS

Tel: 02079115000 x 3437; Fax: 020 7911 5057; email: a.g.woodburn@westminster.ac.uk

\begin{abstract}
Freight modal shift from road to rail is a potential means by which the negative environmental and social impacts of transport can be reduced. This paper explores recent supply chain changes and assesses their impacts on the mode choice decision-making process, specifically addressing the implications for the use of rail. Despite many of the identified changes effectively making the use of rail more difficult, considerable evidence has been found of the potential for rail to attract new traffic. Much of the identified potential is unlikely to materialise, however, without improvements in rail network capability and capacity and a greater customer focus from rail freight operators.
\end{abstract}

Keywords: Rail freight, supply chain, mode choice, transport policy

\section{Introduction}

This paper is concerned with the interface between freight transport policy and supply chain structure and operation, particularly focusing upon the logistical influences on the ability to achieve (or otherwise) the policy targets for rail freight activity in Great Britain. The main aims of the paper are to determine the major interactions between logistical structure and choice of rail as a mode for freight movement and to identify means by which logistical changes may 
assist in increasing the share of freight moved by rail; these aims are expanded in the following section. It is only by developing an understanding of the wider logistical context within which freight transport mode choice decision-making takes place that appropriate actions can be taken. It is hoped, therefore, that this paper will inform the freight transport policy debate and assist with the implementation of policies that will encourage greater use of rail freight. Such a transfer of freight from road to rail is a key element associated with the achievement of a more sustainable transport system. It will succeed only if carried out in a manner that demonstrates an understanding of the way in which supply chains work and which encourages companies, rather than forces them, to consider the use of rail for some of their transport requirements.

\section{Background}

The volume of freight moved by rail in Great Britain suffered a long period of decline from the Second World War through to the mid-1990s. The reductions in rail freight volumes in the early- to mid-1990s continued at a time of increasing road freight traffic and greater concern for the environment. As a result, a shift from road to rail gained more prominence in transport policy. The Royal Commission on Environmental Pollution (1994) argued that the proportion of freight moved by rail should be increased from $6.5 \%$ of tonne kilometres in 1993 to $20 \%$ by 2010.

The emphasis on rail freight can be seen in recent government policy documents, such as the Integrated Transport White Paper (DETR, 1998), Sustainable Distribution daughter document (DETR, 1999), Ten Year Plan (DETR, 2000), Strategic Plan (SRA, 2002) and Freight Progress Report (SRA, 2003a). The latter three documents contain a target to increase rail freight tonne kilometres by $80 \%$ by 2010 . It is not at all clear, however, how this target, and the associated objectives in these reports, should be achieved. Recent rail freight trends have been upwards, with 51\% growth in tonne kilometres between 1994 and 2002, although much of this has come from increased coal movements; non-coal rail freight increased by 
$39 \%$ in this time period (SRA, 2003b). This paper aims to develop a greater understanding of the potential role for rail freight under current and predicted logistical conditions. It is obvious, though, that it is not a straightforward issue. Returning to the levels of even the 1970 s will not be easy, due to the changes in industrial structure (e.g. the decline in heavy industry), transport infrastructure, etc., that have occurred in the intervening period. Rail has not held $20 \%$ of tonne kilometres since 1965 , when the total freight market was far smaller than at present and the operating environment was almost unrecognisable in comparison to the present time. While this RCEP target is more challenging than that in the Ten Year Plan, the scale of change required to meet the latter target will still be substantial. However, other developments such as freight facilities grants (suspended in early 2003, though apparently only temporarily) and new intermodal techniques may assist in attracting traffic to rail.

Given the growth of interest in logistics as a discipline in its own right since the 1970s and the recent emphasis on finding ways to alter the modal split in favour of less environmentallydamaging modes of transport, surprisingly little research has been carried out examining the interactions between logistical structure and modal choice. There have, however, been widespread changes in companies' logistical systems that are likely to have had at least some impact on modal choice. Much previous academic work on the potential for increasing rail's modal share has been at the theoretical level, focusing on operational research, mathematical modelling and demand elasticities (e.g. Cordeau et al (1998), Ferreira (1997), Abdelwahab (1998)). While this type of work is of significance in attempting to quantify some measure of rail freight service quality, and the components thereof, it tends to ignore the other factors that affect rail freight operations. The lack of incorporation of the essentially unquantifiable human and political influences on mode choice and performance in particular means that the theoretical solutions proposed cannot always be implemented successfully in reality.

Other studies (see, for example, FTA, 1995; Plowden and Buchan, 1995; Komor, 1995) have focused almost exclusively on the characteristics of rail freight and the environmental and social benefits, arguing that only relatively minor policy changes are required to effect a significant modal shift from road to rail. A common theme of these studies, however, is a lack 
of a detailed understanding of the extent to which the logistical changes that have taken place in the last 20 years have affected mode choice. As a result, there have been overly-optimistic opinions of the ease of increasing rail's share of freight movements.

Overall, therefore, there appears to have been little overlap between freight mode choice studies and the analysis of logistical systems. Mode choice has traditionally been seen to be low in importance in logistics decision-making. Indeed most recent logistics handbooks (for example Kasilingam, 1998; Wood et al, 1995) and academic texts barely mention the mode of transport to be used at all or, if they do, the assumption is that road will be used. Supply chain research has tended to focus on the importance of human relationships and quality of service factors between stages in the supply chain and has generally neglected the issue of modal choice.

To address this lack of integration of supply chain analysis and use of rail freight, the research reported in this paper had two main objectives. The first of these was to determine the major interactions between logistical structure and choice of rail as a mode for freight movement. There have been many logistical changes that could potentially affect the modal split decision. For example, changes in the location of activity, the structure of manufacturing and distribution networks, the trading relationships between firms and the scheduling of production and distribution may all be important factors that influence mode choice for freight movements. Following on from the first objective was the second: to identify means by which logistical changes may assist in increasing the share of freight moved by rail. This is of direct importance to rail freight operators, whose survival may depend upon attracting new traffic to their services. It is also of significance to other parties (e.g. central government, local authorities, environmental campaigners, general public) who are interested, for various reasons, in transferring freight from road to rail.

This paper focuses on the role of supply chain changes, both upstream and downstream of particular companies, through the analysis of original questionnaire and interview data from British industry. It explores recent changes that have occurred and assesses their impacts on 
the mode choice decision-making process, specifically addressing the implications for the use of rail.

\section{Methodology}

In order to identify the impacts of supply changes on the likely use of rail in the future, a combined questionnaire and interview survey of manufacturers and retailers in a number of different supply chains was conducted during 1999 and 2000. The 100 British companies with the greatest turnover in each of eight manufacturing sectors were targeted, plus the 200 largest retailers. Of this sample of 1,000 companies, 133 completed questionnaires were received. These questionnaires were designed both to gather standard (and generally quantifiable) information about changes to their supply chains and use of rail and to identify companies to subsequently interview in greater depth. While this response rate is low, it is not atypical of such studies and, in itself, is not considered to be a major concern to the robustness of the study, which sets out to develop the understanding of the supply chain issues for rail freight rather than specifically to identify and quantify a specific modal shift based on the survey sample. That said, caution should be exercised when interpreting the findings from the questionnaire and interview analyses, since the findings may not be representative of industry as a whole.

The purpose of the interview phase was primarily to gain a more detailed understanding of the issues through case studies of individual companies. Where possible, interviewees were selected to allow in-depth analysis of specific supply chains rather than just standalone companies. Further, where there was scope, matched pairs of companies (i.e. similar companies at the same stage in the supply chain) were included. This paper focuses mainly on the findings from the interview analysis, supported by the questionnaire responses, with particular emphasis on the likely impacts on rail freight use. For the interviews, as complete a range of companies as possible was included for each supply chain, with the aim of ensuring that they were as representative as possible of the supply chain from source to end user. The 
ideal scenario was that, in a typical supply chain consisting of perhaps five stages, two or three companies at each stage would be interviewed, but this proved to be more of a challenge than expected. From the questionnaire respondents willing to be interviewed, three main supply chains presented themselves:

- paper and publishing;

- food and drink production and retailing; and

- transport equipment.

A total of 39 in-depth interviews were conducted during the second half of 1999 and the first part of 2000, largely on the basis of these three supply chains and the majority of which involved supply chain linkages with other interviewee companies. In the course of the interviews, further linkages were identified in home improvement products and electronic products (see Table 1). In most cases, linkages were between just two stages in the supply chain, although a small number involved three stages and, in some cases, multiple companies per stage. While this did not provide as comprehensive coverage of supply chains as had been desired, it does give a significant volume of original information regarding the operation of significant sections of supply chains and the related interactions with mode choice.

(Insert Table 1 here)

The next section examines key aspects of the recent and predicted logistical changes affecting the interviewee companies, with particular reference to the role for rail freight.

\section{General logistical changes and the role for rail freight}

It was important to gain an understanding of the extent to which logistical operations have actually changed in the survey companies, since if they were static then they would have had no influence at all on mode choice. On the other hand, if there have been significant recent changes then the ability for rail to increase its mode share may have been affected. Table 2 
summarises the extent to which the interview companies have experienced different logistical changes. It is evident that considerable change has taken place in most companies, with just eight interviewees (i.e. $21 \%$ ) stating that their company had not undergone any of these changes during this time period.

(Insert Table 2 here)

Only five interviewees (i.e. 13\%) were sufficiently worried about transport cost increases, either recent or predicted, to believe that their operations would be fundamentally at risk. The overwhelming majority believed transport cost rises to be something beyond their control but whose effects could be contained without drastic action. Without exception, companies were of the opinion that they would be able to cope with any decreases in road-based service quality without having to take major action and that, in any case, their competitors would suffer similarly so competitive advantage would not be lost. However, there was evidence that a growing number of companies had started to pay more attention to mode choice than before, as a result of significant increases in road transport costs and, to a lesser extent road congestion, in recent years.

Eleven interviewees were making use of rail for some of their transport requirements at the time of interview. These were strongly concentrated in the chemicals, paper and publishing and construction and building materials sectors, as can be seen in Table 3. Of those not using rail, just eight (i.e. $21 \%$ ) saw no potential for use in the next five years. Of the remainder, three-quarters stated that they could possibly use rail, but that this would require some restructuring of logistical operations. Just five companies not currently using rail believed that they could easily switch traffic to the mode.

(Insert Table 3 here)

Interviewees were asked to provide an overall appraisal of the scope for rail meeting their transport requirements (e.g. in terms of product type, consignment size, distance, customer 
demands, quality of service required). Across the entire sample, the average proportion of each company's movements potentially viable for rail was 19\% (though with a standard deviation of 19). This reveals a significant potential market for rail, but with large variations between companies. Given that, for ease, interviewees were only asked to approximate the proportion of movements potentially suitable for rail, it would be expected that these would predominantly be longer distance movements so the proportion of tonne kilometres may well be significantly higher. The evidence supports this, since many companies saw potential for long distance British or European flows to transfer to rail. Table 4 summarises this information into the different categories of ease of uptake of services.

(Insert Table 4 here)

This demonstrates that those companies currently using rail believe that its potential to meet their requirements is significantly greater than for other companies. While current users did not generally specify their current proportion of movements that were going by rail, the evidence relating to their rail use from the transcripts suggested that, across the 11 companies, it was well below 10 per cent. Thus, based on the evidence, it appears that rail freight operators would do best to target their efforts at growing the business of their existing customer base.

It would perhaps be expected that there would be a relationship between those companies that had ceased their use of rail in recent years with those who predicted use of rail in the next five years. Dependent upon the relevant factors, if any such relationship existed, it could be normal or inverse. Just two of the interviewees had given up on rail; both predicted they would return to rail in the next five years. Neither company expressed a reluctance to return to rail as a result of the poor performance or treatment by British Rail in the past. Indeed, both companies had been actively trying to return to rail, one with trial movements and the other in discussions to start regular movements. Both believed that rail could still fit into their logistical operations, despite some changes in the intervening period. Given the sample size, 
this evidence of a relationship is largely anecdotal, but Table 5 presents an analysis of the entire questionnaire sample, which included 16 respondents who had ceased using rail.

(Insert Table 5 here)

It is apparent that those companies that gave up using rail in the last 10 years are far more likely to start using it in the next five years than are those that have not had any recent experience of rail freight. The likely uptake of rail freight is 4.5 times greater amongst the previous users than it is for those without recent use. With 13 of the 16 former users predicting a return to rail, there appears to be a convincing trend. The outlook for rail use therefore seems promising. The main purpose of this research, however, was to analyse changes in the underlying logistical factors to determine whether they were making rail use more or less likely in future years. Each interviewee was asked to identify which of a range of company and supply chain trends they expected would occur in the next five years, excluding sales predictions. The findings are shown in Table 6 . Increasing customer requirements, in terms of what service level (e.g. frequency, time window) they demanded from suppliers, was the top ranked factor, mentioned by twice as many interviewees as any other factor. While some of the other predicted developments may be compatible with rail, further increases in requirements from often already demanding customers would be expected to be largely dependent upon road haulage.

(Insert Table 6 here)

Despite this, there was clearly a growing awareness that other factors external to their companies' operations, such as worsening road congestion and the implementation of government policies to increase road haulage costs, would provide more of an incentive to consider rail in the future. Many interviewees were keen to point out that it would take considerably longer than five years to restructure logistical systems to become truly rail friendly since the processes of restructuring are lengthy and there have been several decades of adaptation to the flexibility of road haulage. There are therefore conflicting pressures on 
companies, some encouraging the consideration of rail but with others making this much more difficult and unlikely. Table 7 summarises the likely effects of increased road congestion, increased road haulage taxation and regulation and the introduction of road pricing. It also shows the nature of improvements to the rail network that are necessary to attract new users or greater volumes from existing users.

(Insert Table 7 here)

These figures do not necessarily concur with those presented earlier relating to the likely use of rail since interviewees were being asked to respond to hypothetical scenarios in this case, as opposed to their actual predictions. The rankings of the importance of the attributes in Table 7 are of interest, since it provides a combined assessment of changes in the supply of rail freight and potential negative changes to road freight. It appears that a mixture of positive rail attributes and negative road ones would lead to increased use of rail, rather than predominantly one set of attributes or the other. There is thus a convincing argument for transport policies to address both of these areas as a means of effecting a modal shift to rail. This finding is extremely significant in that it reveals that there are many positive attributes of rail that can feasibly attract new users.

Worsening road haulage also assists in encouraging a greater use of rail, but is not the key issue involved. Shifting from road to rail appears to be just one way in which companies anticipate negating any cost increases or quality decreases. However, a greater proportion of companies would be likely to improve their road efficiency in response to these changes, while a significant number would also look to restructure their company's operations. Very few would consider reducing customer service levels. This analysis has alluded to pressures from others within the supply chain and the influences that they may have on mode choice. This is developed further in the next section. 


\section{Supply chain analysis}

It was reported earlier that the most significant factor responsible for increasing respondents' total demand for freight in the last five years was a change in customer requirements. This suggested that companies downstream in the supply chain had become more demanding of their suppliers and that this had had major implications for the amount, and possibly nature, of freight transport used.

Of the interview sample, 22 (i.e. 56\%) claimed that their customers had become more demanding in the last five years. Largely this resulted from a combination of reduced lead times for delivery to customers and more frequent deliveries of smaller quantities. A small minority of companies had managed to keep control of these issues, for example managing to retain nominated day deliveries to customers or minimum order sizes to justify a delivery. In the main, though, the interviewees had had no option but to allow changes dictated by customers for fear of losing the business to competitors.

Of course, as well as having customers who have become more demanding, the participant companies in this research were generally customers to other companies further upstream in the supply chain. The equal second-most important factor in leading to an increased demand for transport has been the adoption of low inventory strategies such as just-in-time stockholding and production by the participant companies. This will presumably have led to these companies forcing the same sorts of changes onto their suppliers that they themselves have faced from their customers.

Only seven interviewees (i.e. 18\%) had made changes to supplier sourcing in the last five years, although five of those had reduced their stockholding levels and/or the lead times demanded of their suppliers. This may be a result of the majority of interviewees coming from the manufacturing stages at the start and middle of the supply chain, with the customers that they claim to have become more demanding being located further downstream, who were under-represented in the interview phase. Overall, when questionnaire respondents were 
simply asked to rank the top three factors that had influenced their freight demand, these two crucial supply chain measures were ranked second and third with only change in the level of sales placed more highly.

When examining recent changes in transport efficiency within the interviewee companies, six of them (i.e. 15\%) had found that this had worsened while 10 (i.e. $26 \%$ ) stated that they had improved the efficiency of their transport operations. One further company had experienced a combination of deterioration and improvement in efficiency, with no real significant change on balance. Surprisingly, there was no apparent relationship between the direction of efficiency change and the position of the company within the supply chain. A number of companies towards the start of the supply chain had made significant improvements to their transport operations, while others had experienced declining efficiency. Of the five retailers, however, the three who have experienced change had all improved their efficiency.

Examining this in further detail, using the supply chain linkages, reveals a mixed picture as Table 8 reveals. In 10 out of the 25 linkages, there has been no change at all in the efficiency of the two (or three) companies involved. The remainder of linkages revolve around a small number of companies primarily involved in the food and paper industries and thus are not even very representative of the interview sample never mind the population at large. Seven of the 15 involve company A2, a manufacturer of ingredients for the food and paper industries, which is the one that has experienced mixed fortunes in terms of its transport efficiency. Six of the linkages incorporate company 11 , a major food retailer, emphasising the limited strength of this part of the analysis.

(Insert Table 8 here)

In a general sense, it appears that the transport efficiency of companies nearer the beginning of the supply chain has suffered at the expense of those further downstream. Company A2, which features strongly in this analysis, has found that it has come under tremendous pressure from many of its customers to serve them much more frequently and with less notice 
of requirements, particularly in the food side of its business. To some extent it has managed to negate the effects of these demands by improving the efficiency of its distribution to the paper industry, which is much less demanding and more inefficient. This has meant that the overall efficiency has not suffered, but it certainly has to the large food customers. It is interesting to note that $\mathrm{A} 2$ is a current rail user, but this is only for distribution to non-food customers whose requirements are less time constrained and the volumes involved per movement are far greater, which allows the use of rail.

Further down that supply chain, the retailer 11 conceded that its gains in transport efficiency, which have included greater control of the inward movements of products from its suppliers, will in many cases have reduced the efficiency of its suppliers and, indeed, others further upstream. It has, however, begun to work in conjunction with its suppliers to try to remove inefficiencies from the supply chain as a whole, the effect being that movements more suited to rail may be created. This is not the prime motivation for the change, though, which is solely due to retaining or improving profitability through encouraging suppliers to be more efficient in their use of transport and other significant cost elements. The extent to which it will be possible for 11 to assist in achieving such supply chain efficiencies is unclear and is made more difficult by issues of confidentiality within companies along the supply chain.

The analysis thus provides some evidence to support the argument that changes by particular companies in the supply chain, largely towards the customer's end rather than the raw material end, have affected the nature of transport movements throughout the entire supply chain. It has not proved possible to quantify this trend from the interview responses, although the questionnaire evidence lends weight to the general argument that transport efficiency is dictated by supply chain changes to a significant degree. It has been much more difficult to find evidence that relates the impacts of these supply chain changes to the use (or potential use) of rail. The fact that so many companies, particularly out of the larger questionnaire sample, had been using an increasing amount of freight transport as a result of changes in their logistical strategies or those of their customers would suggest that this has made it more difficult for rail to become involved in the supply chain. 
Only one interviewee had had specific discussions with its suppliers regarding ways in which they could restructure the supply chain to allow the use of rail. Perhaps not surprisingly this was $\mid 1$, but even then it was only related to a negligible proportion of supplies, that being long distance movements of wines from southern Europe into Britain. For its domestic business, I1 has not taken any tangible steps to try to establish the potential that may exist for rail as a result of its changing relationships with its customers. For the remainder of interviewees, mode choice was something that was not explicitly considered between companies in the supply chain other than in exceptional circumstances. Company $\mathrm{C} 1$, which is not linked to any others in the sample, was involved in the movement of waste material into landfill sites and was the only interviewee that considered that rail had become more important in the decisions on how changes to the supply chain were effected. It felt that it had benefited from this, in that it had rail-served landfill sites, though the main reason for incorporating rail into the supply chain was due to the growing inefficiencies of road transport in the South East of England as a result of congestion. This has forced companies in that particular supply chain to consider rail at an earlier stage than was previously the case.

These examples though were undoubtedly fairly exceptional cases and in general there has been a neglect of mode choice issues when supply chains have been restructured in the last five years. The nature of the changes that have taken place have tended to continue the trends towards the greater use of transport, often with decreases in efficiency, in order to satisfy growing customer demands. These changes have certainly not been of benefit to rail.

\section{Conclusions and Comment}

It is evident from this research that rail will gain a substantial increase in mode share only if it meets the much more stringent requirements from industry than it ever had to when it was the dominant mode in the past. Without exception, the companies involved in this research primarily used road haulage and had become used to it being flexible and relatively cheap. 
Even in those companies who were using rail, it did not tend to account for a significant proportion of their movements and, at the most optimistic, very few companies interviewed saw rail's potential as being in excess of half of their transport movements. Indeed, over half of the companies interviewed believed that rail could feasibly handle less than $10 \%$ of their movements, while just $37 \%$ of the questionnaire sample expected to be using rail freight in five years time. Changes of this magnitude would still represent a very considerable increase in the uptake of rail freight services though, particularly since it tended to be longer distance flows that would be most likely to switch to rail, so the impacts on tonne kilometres would be greater.

Most logistical changes in recent years have been influenced by increasing customer demands and the impacts that this has had on companies trying to become more efficient to remain competitive. Industry has been generally continuing its move towards a just-in-time (JIT) style of operation, at least adopting the basic principles of leaner production and reduced stockholding, if not full JIT. This has tended to result in smaller volume flows of goods at more frequent intervals, reducing the transport efficiency of the companies supplying these customers and providing limited scope for rail to play a part. This presents an enormous challenge to the rail industry in its attempts to try to serve markets that have been traditionally captive to road. The longer-term changes that have taken place in both the provision of rail freight services and the growing dominance of logistics-based systems across industry as a whole have created a difficult set of circumstances for rail upon which to build significant growth in its customer base and effect a sizeable modal shift from road. There are clearly big expectations amongst manufacturers and retailers that rail will be able to rise to the challenge and meet their demands in the future.

This paper has identified some potential for a shift in freight from road to rail without any substantial restructuring of logistical operations. However, this depends crucially upon the rail service provided being able to fit in with requirements that traditionally rail has not been very strong at managing to handle successfully. A great deal of interest in rail has been identified amongst the companies that took part in the research and many of them had high 
expectations that services to suit their demands would become available within the next five years. Much of the potential traffic has been identified as being fairly easily accessible to rail freight operators as long as they can meet the quality requirements in particular. For rail freight to become a much more serious competitor to road haulage would require considerable restructuring of either the whole logistical operations of companies within supply chains or far-reaching changes to the capabilities of the rail industry to cope with the demands placed upon it. However, should the potential increases that have been identified be realised then this will place rail in a good position to have a sustained increase in its modal share in the longer term. The trends identified in this research, particularly relating to the actions and attitudes of companies towards the use of rail, will continue to be important in future in order to assess the measures required to satisfy policy objectives.

The key issue surrounding the degree of synergy between rail freight supply and demand is currently being developed in an extension to this study. This synergy issue relates both to the ability of rail freight operators to understand and cater for the requirements of potential customers (or indeed to increase rail volumes from existing customers by developing new flows) and the understanding amongst potential customers of what rail freight can do for them. The follow-up study will identify those attributes that have led to rail either being successful or unsuccessful in securing new freight flows and will assist in determining how scarce resources should be targeted in order to achieve growth in rail freight volumes and an increase in rail's mode share. It is anticipated that the findings of the follow-up work will be published in due course. However, given the elapsed time since the survey work analysed in this paper, some comment on the changes that have taken place in the intervening period is appropriate, particularly since the projections made by respondents about rail freight use were for the five year period to $2004 / 05$. It is notoriously difficult to identify specific rail freight users and volumes from public sources, particularly in the non-bulk sectors that many interviewees came from, but it seems certain that the growth in volumes, from existing and new users, has not been of the magnitude identified by the study. 
According to official statistics, rail freight increased by just 3\% between 1999/00 and 2002/03 when measured in tonne kilometres and actually decreased by $5 \%$ in terms of tonnes lifted (SRA, 2003b). For tonne kilometres, the standard measure of activity, this represents a dramatic slowdown from the encouraging annual growth rates of the late-1990s. Thus from the statistics, it seems unlikely that change of the magnitude identified by the survey has occurred, even allowing for any switching between heavy traditional products and lighterweight consumer goods. This brings into sharp focus the caveat stated earlier that the identified modal shift would only occur should the rail service provided be able to fit in with requirements that rail has not tended to cater for well.

The period since 2000 has not been a stable one for British rail freight, with continuing problems relating to the industry structure, extensive network disruption (particularly in the wake of the Hatfield derailment in late-2000) and a lack of funding for new and improved infrastructure identified in various network and strategic plans. Despite these setbacks, there have been positive developments, which demonstrate the ability to cater for some of the traffic types identified in this paper as being available to rail within existing supply chain structures. Admittedly from a very low base, there has been growth in food and drink products using rail; non-food retailers are also emerging as rail freight customers and new-torail flows in other sectors have also occurred. In particular, the emerging competition in rail freight supply is leading to some interesting developments in the movement of "premium logistics" products. Future rail freight growth, including expansion into new traffics, is far from guaranteed, but the evidence from this research is that there is considerable potential to be tapped should the supply-side issues be addressed.

\section{Acknowledgements}

The author would like to thank all of the company representatives who gave their time, knowledge and views for this research. This research was completed whilst the author was employed by Napier University, Edinburgh. 


\section{References}

Abdelwahab, W., 1998, Elasticities of mode choice probabilities and market elasticities of demand: evidence from a simultaneous mode choice/shipment-size freight transport model, Transportation Research E (Logistics and Transportation Review), 34(4), 257-266.

Cordeau, J.F., Toth, P. and Vigo, D., 1998, A survey of optimization models for train routing and scheduling, Transportation Science, 32(4), 380-404

DETR, 1998, A New Deal For Transport: Better for Everyone, White Paper, The Stationery Office, London.

DETR, 1999, Sustainable Distribution: A Strategy, Department of the Environment, Transport and the Regions, London.

DETR, 2000, Transport 2010: The Ten Year Plan, Department of the Environment, Transport and the Regions, London.

Ferreira, L., 1997, Planning Australian freight rail operations: an overview, Transportation Research A, 31(4), 335-348.

FTA, 1995, The Rail Freight Challenge: Increasing Rail Freight by Meeting Customers' Needs, Rail Freight Council, Freight Transport Association, Tunbridge Wells.

Kasilingam, R., 1998, Logistics and Transportation: Design and Planning, Kluwer Academic Publishers, Netherlands. 
Komor, P., 1995, Reducing energy use in US freight transport, Transport Policy, 2(2), 119128.

Plowden, S. and Buchan, K., 1995, A New Framework for Freight Transport, Civic Trust, London.

RCEP, 1994, Transport and the Environment, Royal Commission on Environmental Pollution, London.

SRA, 2002, The Strategic Plan, Strategic Rail Authority, London.

SRA, 2003a, Freight Progress Report 1, Strategic Rail Authority, London.

SRA, 2003b, National Rail Trends 2003/04 Quarter 1, Strategic Rail Authority, London.

Wood, D., Barone, A., Murphy, P. and Wardlow, D., 1995, International Logistics, Chapman and Hall, New York. 
Table 1: Coverage of key supply chains in interviews

\begin{tabular}{|c|c|c|c|c|}
\hline Supply chain & \multicolumn{3}{|c|}{ Coverage of supply chain } & $\begin{array}{c}\text { Companies involved in } \\
\text { supply chain }\end{array}$ \\
\hline Paper/publishing 1 & $\bullet$ & $\bullet$ & & $\mathrm{A} 2 \rightarrow \mathrm{F} 4 / \mathrm{F} 8 / \mathrm{F} 10 / \mathrm{F} 12$ \\
\hline Paper/publishing 2 & $\bullet$ & $\bullet$ & & $\mathrm{F} 7 \rightarrow \mathrm{F} 1 / \mathrm{F} 3 / \mathrm{F} 6 / \mathrm{F} 9$ \\
\hline Food/drink 1 & • & - & - & $\mathrm{A} 2 \rightarrow \mathrm{A} 5 / \mathrm{A} 8 \rightarrow \mathrm{I} 1$ \\
\hline Food/drink 2 & $\bullet$ & $\bullet$ & $\bullet$ & $\mathrm{A} 9 \rightarrow \mathrm{A} 5 / \mathrm{A} 8 \rightarrow \mathrm{I1}$ \\
\hline Food/drink 3 & $\bullet$ & $\bullet$ & $\bullet$ & $\mathrm{A} 2 \rightarrow \mathrm{A} 1 \rightarrow \mathrm{I} 1$ \\
\hline Food/drink 4 & & $\bullet$ & $\bullet$ & $\mathrm{A} 6 \rightarrow \mathrm{I1}$ \\
\hline Food/drink 5 & & $\bullet$ & $\bullet$ & $A 3 \rightarrow I 1$ \\
\hline Food/drink 6 & $\bullet$ & & $\bullet$ & $\mathrm{A} 4 \rightarrow \mathrm{I1}$ \\
\hline Transport equipment 1 & & - & - & $\mathrm{G} 4 \rightarrow \mathrm{D} 2 \rightarrow \mathrm{D} 3$ \\
\hline Transport equipment 2 & & $\bullet$ & $\bullet$ & $\mathrm{G} 4 \rightarrow \mathrm{D} 3$ \\
\hline Transport equipment 3 & & $\bullet$ & $\bullet$ & $\mathrm{D} 1 \rightarrow \mathrm{D} 3$ \\
\hline Transport equipment 4 & & $\bullet$ & $\bullet$ & $\mathrm{D} 2 \rightarrow \mathrm{D} 4$ \\
\hline Home improvement products 1 & $\bullet$ & & $\bullet$ & $\mathrm{F} 11 \rightarrow \mathrm{I3}$ \\
\hline Home improvement products 2 & & $\bullet$ & $\bullet$ & $\mathrm{G} 4 \rightarrow \mathrm{I3}$ \\
\hline Home improvement products 3 & & $\bullet$ & $\bullet$ & $\mathrm{H} 1 \rightarrow \mathrm{I} 3$ \\
\hline Electronic products & & - & - & G1/G3 $\rightarrow$ I5 \\
\hline
\end{tabular}

N.B. Companies are allocated a unique reference code: the letter denotes the sector classification $(A=$ food and drink; $D=$ transport equipment; $F=$ paper and publishing; $G=$ electrical and electronic equipment; $H$ = non-electrical machinery; $I$ = retailers) and the subsequent number is the company identifier within that sector 
Table 2: Logistical changes (in the last five years) within interviewee companies

\begin{tabular}{lc}
\hline Logistical change & $\begin{array}{c}\text { No. of interviewees (and \%) } \\
\text { experiencing change }\end{array}$ \\
\hline Increase in level of sales & $11(28 \%)$ \\
\hline General management reorganisation & $11(28 \%)$ \\
\hline Change in product attributes & $10(26 \%)$ \\
\hline Decrease in no. of company locations & $10(26 \%)$ \\
\hline Increase in no. of company locations & $6(15 \%)$ \\
\hline Decrease in level of sales & $5(13 \%)$ \\
\hline Increase in market area & $4(10 \%)$ \\
\hline Change in location activities & $3(8 \%)$ \\
\hline General change in market area & $1(3 \%)$ \\
\hline
\end{tabular}

Source: author's interviews 
Table 3: Potential use of rail in next five years, by industrial sector

\begin{tabular}{|c|c|c|c|c|}
\hline \multirow[b]{2}{*}{ Industrial sector } & \multicolumn{4}{|c|}{ Use of rail: } \\
\hline & Current & $\begin{array}{c}\text { Could } \\
\text { easily use }\end{array}$ & $\begin{array}{c}\text { Could } \\
\text { possibly use }\end{array}$ & $\begin{array}{c}\text { No } \\
\text { potential }\end{array}$ \\
\hline Food and drink manufacturing (9) & 1 & 1 & 3 & 4 \\
\hline Chemicals and fertilisers (3) & 3 & 0 & 0 & 0 \\
\hline Construction/building materials (1) & 1 & 0 & 0 & 0 \\
\hline Transport equipment (4) & 0 & 1 & 2 & 1 \\
\hline Textiles/clothing/footwear $(0)$ & 0 & 0 & 0 & 0 \\
\hline Paper and publishing (12) & 5 & 0 & 6 & 1 \\
\hline Electrical/electronic equipment (4) & 1 & 0 & 3 & 0 \\
\hline Non-electrical machinery (1) & 0 & 1 & 0 & 0 \\
\hline Retailers (5) & 0 & 2 & 1 & 2 \\
\hline "Total (39) & 11 & $\overline{5}$ & 15 & 8 \\
\hline
\end{tabular}

Source: author's interviews; numbers in brackets indicate number of interviewees in sector 
Table 4: Proportions of movements potentially viable for rail freight

\begin{tabular}{lcc}
\hline & $\begin{array}{c}\text { Mean proportion of goods } \\
\text { potentially viable for rail }\end{array}$ & Standard deviation \\
\hline Current rail users (11) & 40 & 16 \\
\hline Could easily use rail (5) & 17 & 8 \\
\hline Could possibly use rail (15) & 14 & 13 \\
\hline No potential (8) & 0 & - \\
\hline
\end{tabular}

Source: author's interviews; numbers in brackets indicate number of interviewees in category 
Table 5: Influence of previous rail use on likelihood of future use

\begin{tabular}{lcc}
\hline & No. of respondents & \% predicting use in next $\mathbf{5}$ yrs \\
\hline Current rail users & 18 & 100 \\
\hline Gave up rail in last 10 years & 16 & 81 \\
\hline No rail use in last 10 years & 99 & 18 \\
\hline
\end{tabular}

Source: author's questionnaire survey 
Table 6: Most significant predicted company and supply chain trends

\begin{tabular}{ll}
\hline Predicted trend & Percentage of interviewees \\
\hline Increase in service demands made by customers for freight & 46 \\
\hline Change in product attributes & 23 \\
\hline Decrease in number of company locations & 21 \\
\hline Increase in number of company locations & 21 \\
\hline Change in company location activities & 21 \\
\hline Management reorganisation & 15 \\
\hline Change in sourcing patterns & 15 \\
\hline Increase in market area & 13 \\
\hline Decrease in no. of customer delivery locations & 13 \\
\hline
\end{tabular}

Source: author's interviews 
Table 7: Likely effects of hypothetical changes to road and rail service costs and quality

\begin{tabular}{lc}
\hline Change & $\begin{array}{c}\text { \% of interviewees who would potentially } \\
\text { switch to rail (or use more rail) }\end{array}$ \\
\hline Rail service quality improvements & 56 \\
\hline Increased road haulage tax/regulation & 49 \\
\hline Introduction of road pricing & 46 \\
\hline Rail service cost improvements & 44 \\
\hline Increased road congestion & 38 \\
\hline Rail network access improvements & 28 \\
\hline
\end{tabular}

Source: author's interviews 
Table 8: Changes in transport efficiency along supply chains

\begin{tabular}{|c|c|c|c|}
\hline Supply chain linkage & $\begin{array}{c}\text { Efficiency change } \\
\text { for supplier }\end{array}$ & $\begin{array}{l}\text { Efficiency change } \\
\text { for intermediary }\end{array}$ & $\begin{array}{c}\text { Efficiency change } \\
\text { for customer }\end{array}$ \\
\hline $\mathrm{A} 2 \rightarrow \mathrm{A} 1 \rightarrow \mathrm{I} 1$ & $\uparrow \downarrow$ & No change & $\uparrow$ \\
\hline $\mathrm{A} 2 \rightarrow \mathrm{A} 5 \rightarrow \mid 1$ & $\uparrow \downarrow$ & No change & $\uparrow$ \\
\hline $\mathrm{A} 2 \rightarrow \mathrm{A} 8 \rightarrow \mathrm{I} 1$ & $\uparrow \downarrow$ & $\downarrow$ & $\uparrow$ \\
\hline $\mathrm{A} 2 \rightarrow \mathrm{F} 4$ & $\uparrow \downarrow$ & $\mathrm{n} / \mathrm{a}$ & $\uparrow$ \\
\hline $\mathrm{A} 2 \rightarrow \mathrm{F} 8$ & $\uparrow \downarrow$ & $\mathrm{n} / \mathrm{a}$ & $\downarrow$ \\
\hline $\mathrm{A} 2 \rightarrow \mathrm{F} 10$ & $\uparrow \downarrow$ & $\mathrm{n} / \mathrm{a}$ & No change \\
\hline $\mathrm{A} 2 \rightarrow \mathrm{F} 12$ & $\uparrow \downarrow$ & $\mathrm{n} / \mathrm{a}$ & $\uparrow$ \\
\hline $\mathrm{A} 3 \rightarrow \mathrm{I1}$ & $\uparrow$ & $\mathrm{n} / \mathrm{a}$ & $\uparrow$ \\
\hline $\mathrm{A} 4 \rightarrow \mathrm{I1}$ & No change & $\mathrm{n} / \mathrm{a}$ & $\uparrow$ \\
\hline$A 6 \rightarrow I 1$ & No change & $\mathrm{n} / \mathrm{a}$ & $\uparrow$ \\
\hline $\mathrm{A} 9 \rightarrow \mathrm{A} 5 \rightarrow \mathrm{A} 1$ & $\downarrow$ & No change & No change \\
\hline $\mathrm{A} 9 \rightarrow \mathrm{A} 8 \rightarrow \mathrm{A} 1$ & $\downarrow$ & $\downarrow$ & No change \\
\hline $\mathrm{D} 1 \rightarrow \mathrm{D} 3$ & $\uparrow$ & $\mathrm{n} / \mathrm{a}$ & No change \\
\hline $\mathrm{D} 2 \rightarrow \mathrm{D} 4$ & No change & $\mathrm{n} / \mathrm{a}$ & No change \\
\hline $\mathrm{F} 7 \rightarrow \mathrm{F} 1$ & No change & $\mathrm{n} / \mathrm{a}$ & No change \\
\hline $\mathrm{F} 7 \rightarrow \mathrm{F} 3$ & No change & $\mathrm{n} / \mathrm{a}$ & No change \\
\hline $\mathrm{F} 7 \rightarrow \mathrm{F} 6$ & No change & $\mathrm{n} / \mathrm{a}$ & $\uparrow$ \\
\hline $\mathrm{F} 7 \rightarrow \mathrm{F9}$ & No change & $\mathrm{n} / \mathrm{a}$ & No change \\
\hline $\mathrm{F} 11 \rightarrow \mathrm{I3}$ & No change & $\mathrm{n} / \mathrm{a}$ & No change \\
\hline $\mathrm{G} 1 \rightarrow \mid 5$ & No change & $\mathrm{n} / \mathrm{a}$ & No change \\
\hline G3 $\rightarrow$ I5 & No change & $\mathrm{n} / \mathrm{a}$ & No change \\
\hline $\mathrm{G} 4 \rightarrow \mathrm{D} 2 \rightarrow \mathrm{D} 3$ & No change & No change & No change \\
\hline $\mathrm{G} 4 \rightarrow \mathrm{D} 3$ & No change & $\mathrm{n} / \mathrm{a}$ & No change \\
\hline G4 $\rightarrow \mid 3$ & No change & $\mathrm{n} / \mathrm{a}$ & No change \\
\hline $\mathrm{H} 1 \rightarrow \mathrm{I} 3$ & $\downarrow$ & $\mathrm{n} / \mathrm{a}$ & No change \\
\hline
\end{tabular}

Key: $\uparrow$ - improvement; $\downarrow$ - worsening; $\uparrow \downarrow$ - combination of improvement and worsening due to multiple changes taking place; n/a - not applicable; supplier $\rightarrow$ intermediary (where applicable) $\rightarrow$ customer (e.g. A2 is supplier, A1 is intermediary and 11 is customer in first case)

Source: author's interviews 